Editorial

\title{
Recent Advances on Analysis Methods and Modelling Approaches for Seismic Assessment and Design of Infilled RC Buildings
}

\author{
André Furtado $\mathbb{D}^{1},{ }^{1}$ Maria Teresa De Risi $\left(\mathbb{D},{ }^{2}\right.$ Hemchandra Chaulagain $\left(\mathbb{D},{ }^{3}\right.$ \\ Ibrahim Misir $\left(\mathbb{1},{ }^{4}\right.$ and Tanja Šipoš $\left(\mathbb{1}^{5}\right.$ \\ ${ }^{1}$ CONSTRUCT-LESE, Faculdade de Engenharia da Universidade do Porto, Porto, Portugal \\ ${ }^{2}$ Department of Structures for Engineering and Architecture, University of Naples Federico II, Naples, Italy \\ ${ }^{3}$ School of Engineering, Pokhara University, Pokhara, Nepal \\ ${ }^{4}$ Dokuz Eylul University, School of Engineering, Izmir, Turkey \\ ${ }^{5}$ Faculty of Civil Engineering and Architecture, Osijek, Croatia \\ Correspondence should be addressed to André Furtado; afurtado@fe.up.pt
}

Received 31 October 2019; Accepted 1 November 2019; Published 6 August 2020

Copyright ( 92020 André Furtado et al. This is an open access article distributed under the Creative Commons Attribution License, which permits unrestricted use, distribution, and reproduction in any medium, provided the original work is properly cited.

One major challenge of earthquake risk mitigation is the assessment of existing buildings not designed with modern codes and the development of effective strengthening techniques. The design of new building structures is also of paramount importance since infills are still currently neglected (or a lot of information is missing) by most of the seismic codes. Special attention should be paid to reinforced concrete (RC) frame structures with masonry infill panels, as proved by their poor performance in recent earthquakes. Accurate modelling strategies and appropriate seismic assessment methodologies for new or existing infilled buildings are crucial to understand their behaviour and to develop efficient and appropriate mitigation measures to prevent high level of damage, casualties, and economic losses. The effect of the combined in-plane and out-of-plane behaviour interaction of the infill masonry walls in the RC structure seismic behaviour, the local shear interaction between the RC frame and the masonry infill, the development of analytical formulations that could help design engineers are still open issues, among others, on this topic.

The focus of this Special Issue is on recent advances on analysis methods and modelling approaches for seismic assessment of infilled RC buildings. Some of the most significant recent developments in the topic of computational methods to simulate infilled RC structure seismic behaviour and their applications in structural and seismic engineering problems are herein presented. Furthermore, experimental works in the field of as-built and/or retrofitted infilled RC frames are also part of the Special Issue.

A total of 14 papers were submitted, from which a total of 6 papers have been finally selected to integrate the present issue, which accentuates the need, the interest, and the importance of this topic. The topics addressed in the papers belong to different subtopics across the seismic behaviour of infilled RC structures, such as the seismic performance of bare frame and infilled RC frame structures, the shaking table test of hollow rectangular RC columns, the building earthquake damage analysis using terrestrial laser scanning data, the shake table response of unreinforced masonry and reinforced concrete elements of special moment resisting frame, and a literature review on the experimental studies carried out on infilled RC frames focusing in particular the seismic behaviour of the masonry infill walls.

\section{Conflicts of Interest}

The guest editors have no conflicts of interest regarding the publication of this special issue.

André Furtado

Maria Teresa De Risi Hemchandra Chaulagain

Ibrahim Misir

Tanja Šipoš 